\title{
La lematización de los pronombres en los diccionarios actuales
}

\author{
José-Álvaro Porto Dapena \\ Universidad de A Coruña
}

La lematización de las entradas de un diccionario viene determinada, como es bien sabido, por unas reglas concretas y precisas que normalmente han sido fijadas por la tradición lexicográfica de la lengua de que se trata ${ }^{1}$. El problema atañe, lógicamente, tan solo a los casos en que la palabra-entrada presenta variabilidad, ya sea por su polimorfismo gráfico (y a veces también fónico) o por tratarse de un vocablo con flexión. En esta última circunstancia no hace falta recordar que se elige como lema una de sus formas flexionales -que, evidentemente, las representa a todas- $y$, todo lo más, se acompaña, secundariamente, con alguna otra, esta vez indicada normalmente con la pura desinencia o terminación en que ésta se halla incluida. Y así, por ejemplo, en nuestra lexicografía española es normal que la entrada de un verbo venga dada exclusivamente por el infinitivo, mientras que la de un nombre con flexión de género se representa mediante la forma masculina (indudablemente por ser la más neutra desde el punto de vista semántico), a la que suele añadirse, separada por una coma, la correspondiente terminación femenina.

Todos los diccionarios del español -y de las lenguas occidentales en general- siguen este mismo procedimiento, $y$, por lo tanto, las discrepancias que pueden encontrarse entre ellos son desde luego mínimas por no decir nulas. No podemos decir, sin embargo, lo mismo cuando de la lematización de pronombres se trata, circunstancia para la que por cierto no ha sido fijada todavía ninguna normativa universalmente

1 Véase a este propósito, por ejemplo, lo que expongo en Porto Dapena (2002: 174 y ss.). 
aceptada. Por ejemplo, mientras es ya prácticamente unánime registrar en artículos independientes todas y cada una de las formas de los pronombres de primera y segunda persona -lo que, dicho sea de paso, entra en clara contradicción con el principio general de representar mediante una sola forma las palabras flexivas-, las discrepancias llegan a su punto álgido en la lematización del pronombre de tercera persona, cuestión en la que casi se puede decir que cada diccionario sigue sus propias normas. Pero la cosa no para ahí, puesto que estas discrepancias, aunque ciertamente de menor importancia, se extienden asimismo al llamado artículo determinado al lado de otros pronombres, como los demostrativos, posesivos y relativos así como al reflexivo y hasta a algunos indefinidos.

En el presente artículo me propongo poner de manifiesto estas discrepancias en los principales diccionarios del español actual ${ }^{2}$, tratando al mismo tiempo de ahondar en sus posibles causas y, por consiguiente, en la problemática planteada en ese aspecto lexicográfico por este tipo de palabras. Y mi último objetivo consistirá, lógicamente, en proponer soluciones exentas de las incongruencias que en general vienen presentando los diccionarios de nuestra lengua.

\section{CUESTIONES PREVIAS}

No voy a entrar aquí, naturalmente, en la problemática en torno a la naturaleza de los pronombres; es decir, si se trata de una categoría o clase de palabras opuesta al nombre y, por lo tanto, independiente de éste, cuestión, como es sabido, ampliamente discutida entre los teóricos de la Gramática ${ }^{3}$. Es importante, sin embargo, determinar la extensión o amplitud concedida al pronombre, puesto que ello sí tendrá repercusiones,

2 Concretamente, los diccionarios a que me voy a referir son los siguientes: $D R A E$, DUE, Anaya, Clave, Salamanca, DEA, DGILE, Lema, DUEAE, Alcalá, SGEL y DCR (véase bibliografía al final).

3 Pueden consultarse, entre otros, Álvarez Martínez (1984: 49-67), Barrenechea (1969: 27-70), Benveniste (1973: 172-178), Escavy Zamora (1987), Hjelmslev (1972: 253 y ss), Molina (1078: 237-53), Mondéjar (1977: 37-55) y Olza (1973). 
como veremos, no solo en la categorización dada en los diccionarios a ciertas entradas, sino también en lo que ahora nos interesa estudiar, que es la lematización. Nosotros vamos a partir aquí de la idea del pronombre como palabra gramatical con función nominal, es decir, que tanto puede tener función sustantiva o de núcleo del sintagma nominal, como adjetiva o de elemento adjunto o adyacente, punto de vista que difiere, como puede verse, de aquel otro, muy extendido en nuestra tradición gramatical, según el cual se opone pronombre a adjetivo. Es el caso, por ejemplo, de la Real Academia en su Gramática (1962: 36), donde aparecen distinguidos los pronombres demostrativos de los correspondientes adjetivos. No así por cierto en el Esbozo (1973: 202 y ss.), donde se parte del supuesto de que tanto los demostrativos como los posesivos junto con algunos indefinidos y relativos pueden funcionar como sustantivos y adjetivos. Y no solo esto, sino que el artículo, aunque sin llegar a clasificarlo como pronombre, se estudia en este último tratado gramatical en el mismo capítulo que los demostrativos (1962: 213). Para nosotros, al tratarse los pronombres de palabras gramaticales -esto es, de carácter categoremático, como diría Coseriu-, también el artículo será un tipo de pronombre al igual que todos los tradicionalmente llamados adjetivos determinativos o, como hoy se prefiere, determinantes.

Si ahondamos, sin embargo, un poco en las causas del desacuerdo de nuestros diccionarios a la hora de lematizar las formas pronominales, desde luego observaremos que no solo obedece al hecho de que se incluya o no en la clase pronominal la función adjetiva -ello explicaría, por ejemplo, que muchos diccionarios, al oponer pronombres y adjetivos, registren como entradas independientes los neutros esto, eso, aquello-, sino ante todo y en primer lugar a la delimitación, en el caso concreto de los pronombres personales, de los distintos paradigmas flexionales, que además presentan formas morfonológicamente muy distintas, cicunstancia que parece aconsejar su registro bajo lemas independientes dentro de la nomenclatura del diccionario.

Pero antes de entrar en la consideración de estos y otros puntos, una cuestión previa que quizá convendría plantearse en primer lugar es la de si las palabras gramaticales pueden o no figurar como entradas en los diccionarios. Evidentemente, no voy a entrar aquí en esta discusión teó- 
rica por cierto abordada ya por otros autores ${ }^{4}$; me limitaré a constatar que todos los diccionarios generales de la lengua -no digamos los que se ocupan muy especialmente del aspecto gramatical de las palabrasregistran de hecho no solo los pronombres, sino también los elementos de relación (preposiciones y conjunciones), así como ciertos sufijos y sobre todo prefijos. Como observa S. Gili Gaya (1954), aunque su tratamiento corresponde más propiamente a la Gramática, no deben estar, sin embargo, ausentes del Diccionario, aun cuando en éste se traten de un modo más sumario. De hecho una obra lexicográfica que prescindiese absolutamente de lo gramatical no solo en este sino en otros aspectos sería de todo punto inviable, lo que quiere decir que los límites entre Gramática y Diccionario son y serán siempre imprecisos.

\section{LOS PRONOMBRES PERSONALES}

Los paradigmas de los pronombres personales vienen en principio estableciéndose de acuerdo con la indicación de la personas, razón por la que se distinguen pronombres de primera, de segunda y de tercera persona, dividida a su vez esta última en dos subparadigmas: el correspondiente al de la que podríamos llamar tercera persona "oblicua" por una parte, y el de la "reflexiva" por otra. En total vienen admitiéndose, como es bien sabido, cuatro paradigmas de pronombres personales, aun cuando ello resulta discutible, sobre todo en el caso de las formas correspondientes a los plurales de la primera y segunda persona, habida cuenta de que, como se ha señalado reiteradamente, las formas nosotros y vosotros no son propiamente los plurales de yo y tú, sino que indican una pluralidad de personas en la que, respectivamente, se encuentra la primera y la segunda; es decir,

$$
\begin{aligned}
& \text { nosotros }=y o+(t u ́)+(e ́ l \text { o ellos }) \\
& \text { vosotros }=\text { tú }+(\text { él o ellos }) .
\end{aligned}
$$

Ahora bien, esto podría utilizarse como argumento para considerar estas formas de plural como integradoras de sendos paradigmas independientes de las de singular, con lo que, en vez de cuatro, tendríamos

4 Me remito, por ejemplo, a Alvar Ezquerra (1993: 91-95). 
seis paradigmas diferentes de pronombres personales. No hace falta observar que, desde este punto de vista, se justificaría el tratamiento -con su consiguiente lematización- de cada una de estas series de pronombres personales en artículos lexicográficos independientes.

Otra discusión que cabría introducir aquí sería el carácter pronominal de las formas clíticas o átonas, que algunos autores interpretan más bien como una especie de morfemas verbales encargados de establecer la concordancia con los objetos directo o indirecto, lo que determinaría en español la existencia de una verdadera conjugación objetiva ${ }^{5}$. Y así E. Alarcos Llorach (1994: 198 y ss.), siguiendo este punto de vista, prefiere llamar a estas formas "incrementos personales átonos del verbo". Que yo sepa, no ha aparecido todavía ningún diccionario que defienda este punto de vista; pero con ello se justificaría la separación de las formas me, te, le, etc. como cabeceras o lemas de artículos independientes.

Los pronombres personales, por otro lado, presentan, como es sabido, una multiplicidad de formas que en un gran porcentaje de casos no son morfológicamente derivables unas de otras, al presentar una fisonomía fónica y gráfica muy distinta. Es el caso, de yo, mí, me, conmigo o de tú, ti, te, contigo, por citar tan solo dos ejemplos. Ello obliga, como ya queda señalado, a introducir cada una de esas formas como entradas independientes, en lugar de darlas por supuestas bajo una sola que funcionara como lema o representanción de toda la flexión.

\subsection{LEMATIZACIÓN DE LOS PRONOMBRES DE PRIMERA Y SEGUNDA PERSONA}

En lo que a los pronombres de primera y segunda persona de singular se refiere, todos los diccionarios consultados, excepto el de Cuervo, coinciden en la lematización, pues siguen, efectivamente, el procedimiento de registrar mediante lemas independientes cada una de las correspondientes formas. Esto supuesto, tenemos la siguiente situación ${ }^{6}$ :

5 Véase a este respecto, por ejemplo, Llorente y Mondéjar (1974).

6 En adelante el signo (+) indica que la forma que encabeza la columna aparece como lema, el signo (-) que no aparece como tal, y el signo (o) que es un sublema, esto es, que se registra en el enunciado, pero sin ser lema propiamente dicho. 


\begin{tabular}{|l|c|c|c|c|c|c|c|c|}
\cline { 2 - 10 } \multicolumn{1}{c|}{} & conmigo & contigo & me & te & mi & ti & tú & $y o$ \\
\hline DRAE & + & + & + & + & + & + & + & + \\
\hline DUE & + & + & + & + & + & + & + & + \\
\hline DEA & + & + & + & + & + & + & + & + \\
\hline Clave & + & + & + & + & + & + & + & + \\
\hline Salamanca & + & + & + & + & + & + & + & + \\
\hline SGEL & + & + & + & + & + & + & + & + \\
\hline Anaya & + & + & + & + & + & + & + & + \\
\hline DUAE & + & + & + & + & + & + & + & + \\
\hline Lema & + & + & + & + & + & + & + & + \\
\hline Alcalá & + & + & + & + & + & + & + & + \\
\hline DGILE & + & + & + & + & + & + & + & + \\
\hline DCR & - & - & - & - & - & - & + & + \\
\hline
\end{tabular}

Se exceptúa, como vemos el $D C R$ de Cuervo, donde aparecen lematizadas únicamente las formas yo y tú.

Algo semejante hay que decir respecto a la primera y segunda personas de plural: en primer lugar, todos los diccionarios, exceptuando también el de Cuervo, utilizan como lemas todas y cada una de las formas a no ser el femenino nosotras, que se registra como forma secundaria o sublema en el propio enunciado a continuación del lema ${ }^{7}$. No distinguen por lo demás entre nos tónico y átono, que van encabezados por un único lema. Es curioso, sin embargo, señalar que en el $D E A$ aparecen dos lemas representados por esta forma: un $\operatorname{nos}^{l}$ con remisión

7 Reservo el nombre de lema exclusivamente para la parte del enunciado del artículo lexicográfico sometida a orden alfabético (véase a este propósito Porto Dapena 2002: 184) y llamo secundarias o sublemas a aquellas otras formas que aparecen en el enunciado o cabecera a continuación del lema. Algunos - pienso que equivocadamentellaman lema a todo el enunciado. 
a nosotros -y que por lo tanto en principio nos haría pensar en la forma átona- junto a un $n^{2}{ }^{2}$, bajo el que, contra lo que era de esperar, no solo se estudia la forma tónica sino también la átona, circunstancia que deja inexplicado e inexplicable el desdoblamiento realizado de nos. Digno de destacarse es también el $D C R$ de Cuervo, que además de no lematizar todas las formas de estos pronombres utiliza incoherentemente como lemas las formas nos para la primera persona y, en cambio, vosotros para la segunda, incluyendo como sublemas todas las demás formas, razón por la que surgen dos cabeceras asimétricas:

\section{nos, nosotros, as}

vosotros, vosotras, vos, os.

Es decir, nos encontramos ante dos enunciados acumulativos, en que se registra todo el paradigma flexional, si bien en un orden diverso -lo que, evidentemente, no favorece la homogeneidad del diccionario- e incluso en una formulación también distinta: mientras en el último caso la forma femenina aparece entera, en el primero está representada únicamente por la terminación as.

Existe por cierto también una falta de unanimidad en los diccionarios a la hora de presentar la terminación femenina de estos pronombres: mientras la mayoría sigue la norma académica consistente en indicarla mediante la última sílaba, esto es, tras, otros -concretamente el $D U E$ y el $S G E L$ junto, como acabamos de ver, con el $D C R$ - adoptan un criterio que podríamos calificar de morfológico, indicándola mediante la desinencia correspondiente as. A esto hay que añadir que, mientras en unos dicha terminación aparece con guión, para indicar precisamente que se trata del segmento final de una palabra (así, en el $D U E, D E A$, $S G E L$, Anaya, DUAE, LEMA y DGILE), en otros se presenta, sin embargo, sin guión, como hace el DRAE, el Salamanca y el Alcalá. En ningún caso, excepto el ya señalado del $D C R$, la forma femenina aparece representada en su integridad.

Así pues, de acuerdo con lo dicho tenemos el siguiente cuadro: 


\begin{tabular}{|l|c|c|c|c|c|c|}
\cline { 2 - 7 } \multicolumn{1}{c|}{} & nos & nos & nosotros & os & vos & vosotros \\
\hline DRAE & - & + & + & + & + & + \\
\hline DUE & - & + & + & + & + & + \\
\hline DEA & + & + & + & + & + & + \\
\hline Clave & - & + & + & + & + & + \\
\hline Salamanca & - & + & + & + & + & + \\
\hline SGEL & - & + & + & + & + & + \\
\hline Anaya & - & + & + & + & + & + \\
\hline DUAE & - & + & + & + & + & + \\
\hline Lema & - & + & + & + & + & + \\
\hline Alcalá & - & + & + & + & + & + \\
\hline DGILE & - & + & + & + & + & + \\
\hline DCR & - & + & + & + & + & + \\
\hline
\end{tabular}

Si exceptuamos el $D E A$, que trata en un solo artículo cada uno de los paradigmas correspondientes a la primera persona de singular (bajo el lema yo), segunda de singular (bajo el lema tú), primera persona de plural (nosotros) ${ }^{8}$ y segunda persona de plural (lema vosotros), realizando por lo tanto una remisión a éstos en los lemas correspondientes a las otras formas, en la generalidad de los diccionarios cada lema encabeza un artículo independiente, de modo que los paradigmas flexivos correspondientes a estos pronombres, en lugar de ser descritos en la microestructura, como sería a nuestro modo de ver lo lógico, aparecen desperdigados a lo largo de la macroestructura, lo que quiere decir que, en la práctica, los diccionarios no establecen propiamente los paradigmas flexionales de estos pronombres ${ }^{9}$. Por eso, indudablemente, el proceder del

8 No incluye aquí, sin embargo, la forma tónica nos, que estudia bajo el lema correspondiente.

9 De los diccionarios aquí analizados habría que exceptuar el $D U E$, que trata dichos pa- 
$D E A$, que no deja de ser una novedad en la lexicografía española, es sin duda el más adecuado, aunque, a mi juicio, comete una pequeña incoherencia al no incluir, por una parte, en el paradigma de la segunda persona la forma tónica vos, que estudia en artículo independiente -lo que, por otro lado, le lleva a tratar la forma átona os tanto en este artículo como en el correspondiente a vosotros-, y lo mismo ocurre con la forma tónica nos del pronombre de primera persona.

\subsection{LEMATIZACIÓN DE LOS PRONOMBRES DE TERCERA PERSONA: FORMAS TÓNICAS}

Es, de todas maneras, en la lematización de los pronombres de tercera persona donde, como queda dicho, los diccionarios presentan mayores discrepancias. Ante todo, lo primero que cabe señalar a este respecto es la total ausencia de estos pronombres en el $D C R$ de Cuervo tanto en sus formas tónicas como átonas y tanto en las oblicuas como reflexivas, lo que constituye sin duda un fallo de una extremada gravedad, tratándose como se trata de un diccionario esencialmente gramatical: resulta, desde luego, impensable que un diccionario que se preocupa especialmente por la construcción no diga, por ejemplo, ni una palabra sobre la sintaxis de la forma se ni sobre problemas tan importantes en el español de todos los tiempos como son el leísmo y el laísmo o loísmo. Ya en 1980 señalaba yo ${ }^{10}$ el lapsus cometido cuando se preparó la edición del primer fascículo del tercer volumen de esta obra, al no incluir - contra el propósito del propio Cuervo- el pronombre él, ella, ello, a cuyo artículo se remite por cierto en el apartado dedicado a la etimología de el, la, lo, que sí, en cambio, aparece justamente registrado en este diccionario ${ }^{11}$.

radigmas en el artículo de desarrollo gramatical correspondiente a pronombre, que en el segunda edición aparece, como se sabe, fuera del cuerpo de la obra, en el apéndice II.

10 Véase Porto Dapena (1980: 162).

11 Hablando de ausencias, que son muchas, en el $D C R$, una que llama especialmente la atención es la representada por las entradas de la $L$ a partir de ligero, último artículo de esta letra. Da la impresión de que los redactores decidieron en algún momento incluir la $L L$ dentro de $L$, pero luego se olvidaron de continuarla, dejando fuera palabras -previstas ya por Cuervo- como loar, lograr, lucir, lucha, luchar o, por supuesto, luego. 
Los demás diccionarios consultados para la realización del presente estudio registran, todos sin excepción, el pronombre de tercera persona tanto oblicuo como reflexivo, aunque sin seguir en su lematización una pauta uniforme. Esta lematización, efectivamente, oscila desde la efectuada con todas y cada una de las formas, tanto tónicas como átonas, hasta la representada por los que las agrupan total o parcialmente y de una forma relativamente aleatoria dentro de una o varias cabeceras. Las soluciones, como vamos a ver a continuación, son extremadamente variadas.

Circunscribiéndonos en primer lugar a las formas tónicas no reflexivas, tenemos la siguiente situación:

\begin{tabular}{|l|c|c|c|c|c|}
\cline { 2 - 6 } \multicolumn{1}{c|}{} & él & ella & ello & ellos & ellas \\
\hline DRAE & + & $o$ & + & + & $o$ \\
\hline DUE & + & + & + & + & - \\
\hline DEA & + & + & + & - & - \\
\hline Clave & + & + & + & + & $o$ \\
\hline Salamanca & + & + & + & + & $o$ \\
\hline SGEL & + & + & + & + & + \\
\hline Anaya & + & + & + & - & - \\
\hline DUAE & + & + & + & + & $o$ \\
\hline Lema & + & + & + & + & $o$ \\
\hline Alcalá & + & + & + & - & - \\
\hline DGILE & + & + & + & + & $o$ \\
\hline DCR & - & - & - & - & - \\
\hline
\end{tabular}

Así pues, coinciden cinco diccionarios (Clave, Salamanca, DUAE, Lema y DGILE), que utilizan como lemas independientes todas las formas, excepto el plural femenino ellas, que lo incluyen, no obstante, en el mismo enunciado que el masculino ellos. También coiciden $D E A$, Anaya y Alcalá, que lematizan tan solo las formas singulares. Los de- 
más diccionarios difieren todos: en primer lugar el DRAE registra como lemas él, ello, ellos, e introduce las formas femeninas junto a la correspondiente masculina en el mismo enunciado o cabecera de artículo; por su parte el $D U E$ lematiza todas las formas excepto la del plural femenino, y, finalmente, el $S G E L$ registra todas las formas sin excepción en lemas independientes.

Es interesante señalar que ningún diccionario acumula en el mismo enunciado todas las formas del paradigma, que más bien aparecen en enunciados independientes y, por lo tanto, tratadas asimismo independientemente. Solo las formas femeninas aparecen en algunos casos junto a la masculina, tomada como lema; así, en el $D R A E$ aparecen los enunciados

\section{él, ella \\ ellos, llas}

esto es, con la forma femenina completa en el singular y, en cambio, representada por la sola terminación sin guión en el plural. El mismo proceder encontramos en el Lema, DUAE y Clave, si bien en este caso en el plural se registra la forma femenina completa. En el Salamanca, sin embargo, solo en el artículo ellos se incluye también el femenino, esta vez solo mediante la terminación llas sin guión. Es interesante señalar, finalmente, el proceder del $D E A$ y del Anaya, que registran -solo en el singular- la forma femenina (completa) junto a la masculina él, lo que no impide que dicha forma aparezca a su vez registrada en lema independiente, aunque con remisión a él. Este mismo proceder, por cierto, aparece en el Clave, donde sin embargo bajo el lema ella no se remite a él, ella.

Punto en el que existe unanimidad en los diccionarios es la no inclusión de la forma neutra ello en el enunciado correspondiente al lema él, en contra de lo que sería lógico, al menos en los casos en que se opta -como hacen el DRAE, DEA, Lema, DUAE, DGILE, Clave y Anayapor un enunciado polimórfico, esto es, con la forma masculina y femenina. No parece, efectivamente, haber una clara justificación en estos casos, para lematizar y estudiar en artículo independiente la forma ello, como no sea el hecho de que éste presenta una acepción especial como 
sustantivo empleado en el ámbito de la Psicología; pero por esa razón también habría que independizar ella, puesto que, frente a él, puede formar parte de expresiones del tipo allí fue ella, etc. Semejante proceder pienso que tiene su origen en la doctrina gramatical de Bello (1981: 249-268), quien, como es sabido, disocia las formas él, ella, que considera formas tónicas del artículo, de ello, que sería un sustantivo neutro paralelo a los demostrativos esto, eso, aquello y a otros como poco, algo, nada, etc. De hecho el Diccionario de autoridades incluye en un mismo enunciado las tres formas de género del pronombre personal de tercera persona, es decir,

\section{él, ella, ello}

y tal es el proceder de la Academia en las sucesivas ediciones de su diccionario vulgar hasta $1884^{12}$. Supongo que fue a partir de esta decisión académica como se introdujo en nuestra lexicografía la costumbre de registrar el neutro en lema aparte.

Particularmente destacable por cierto es el caso del $D E A$, que bajo la cabecera él, ella estudia todas las formas del pronombre personal de tercera persona, incluso las átonas, señala por otro lado entre paréntesis las formas correspondiente de plural, y no cita para nada el neutro ello, que trata, de acuerdo con lo dicho, en artículo independiente, categori-

12 Cabe, no obstante, señalar que a partir de la edición de 1791, él, ella, ello se estudian como subentradas dentro del artículo el (artículo), situación que se mantiene hasta la de 1884, en que se registra el (artículo) seguido, en artículo independiente, de él (pronombre personal) encabezado con esta única forma, es decir, sin la femenina y neutra. Este último modo de proceder se mantiene hasta la edición de 1992, en que, por el contrario, se registran las cuatro formas junto a él, es decir, en el enunciado

\section{él, ella, ellos, ellas}

y a continuación el lema el (artículo). El orden se invierte en la última edición de 2002, colocando el artículo en primer lugar, ahora con todas sus formas de singular,

\section{el, la, lo}

y a continuación las del pronombre personal tal como quedó descrito, es decir, con solo las formas masculina y femenina de singular. Cabe interpretar, pues, que en esta última lematización haya influido posiblemente el diccionario Clave. Pero, sea como fuere, subrayemos la vacilación de la Academia en las sucesivas ediciones de su Diccionario. 
zándolo de un modo vago como "pronombre personal en singular" (pron pers sg).

\subsection{FORMAS ÁTONAS DE TERCERA PERSONA}

En lo que se refiere a las formas átonas, la situación puede resumirse en el siguiente cuadro:

\begin{tabular}{|l|c|c|c|c|c|c|c|c|}
\cline { 2 - 10 } \multicolumn{1}{c|}{} & la & las & le (m. y f.) & le (n.) & les & lo (m.) & lo (n.) & los \\
\hline DRAE & + & + & + & - & + & + & - & + \\
\hline DUE & + & + & + & - & + & + & - & + \\
\hline DEA & + & - & + & + & - & + & + & - \\
\hline Clave & $o$ & + & + & - & + & + & + & + \\
\hline Salamanca & + & + & + & - & + & + & - & + \\
\hline SGEL & + & + & + & - & + & + & - & + \\
\hline Anaya & + & - & + & - & - & + & - & - \\
\hline DUEAE & + & - & + & - & - & + & - & - \\
\hline Lema & + & - & + & - & - & + & - & - \\
\hline Alcalá & + & - & + & - & - & + & - & - \\
\hline DGILE & + & - & + & + & - & + & - & - \\
\hline DCR & - & - & & - & - & - & - & - \\
\hline
\end{tabular}

Pero la situación es todavía más compleja de lo que a primera vista puede ofrecernos el cuadro, ya que son muchos los diccionarios que bajo los lemas la, las y lo, los incluyen no solo el pronombre de tercera persona, sino también el artículo. Tal es el proceder concretamente del DUE, SGEL, Clave, Salamanca, Anaya, DUEAE, Lema, DGILE y Alcalá. Así pues, solo el $D R A E$ y el $D E A$ registran estas formas independientemente de sus homónimas del artículo, colocándoles por ello un superíndice, el número 2, en el Diccionario de la Academia, y el 3 en el de M. Seco. Éste por cierto registra asimismo con lemas distintos la for- 
ma masculina, que aparece como $l o^{2}$, y la neutra bajo $l o^{3}$, distinción que se repite en el Clave, el cual por su lado no lematiza el femenino singular, al situarlo al lado del masculino lo en un mismo enunciado, es decir,

\section{lo, la}

frente a los correspondientes plurales, que se presentan sin embargo en lemas independientes. Esta falta de simetría se debe muy probablemente a la necesidad de distinguir -para no tener que utilizar un índice- esta forma lo de la del correspondiente neutro; pero aun así creemos que los plurales bien podrían haberse estudiado bajo ese mismo lema o, al menos, bajo el enunciado

\section{los, las}

paralelamente a lo que en este mismo diccionario se hace con las formas tónicas ellos, ellas.

Digna de destacarse es por cierto otra peculiaridad -en este caso exclusiva- del DEA de Seco, al aparecer también en él dos lemas para la forma $l e$ : un $l e^{l}$ correspondiente al masculino y femenino, donde se remite a él, junto a un $l e^{2}$, representante del neutro y que, por lo tanto, se halla remitida a ello. La solución, debida lógicamente a la separación que, como hemos visto, aquí se hace del neutro como pronombre independiente, pienso que no se justifica no solo por lo discutible que resulta esa separación, sino sobre todo porque es artificial postular la existencia en nuestro pronombre de dos formas le, que, evidentemente, poseen la misma etimología y desde luego idéntica función.

No ocurre, sin embargo, lo mismo con lo, que por el contrario representa dos formas etimológicamente distintas, el masculino y el neutro, distinción que, según acabamos de observar, se hace -pienso que muy acertadamante- en el DEA y en el Clave. No parece, por lo tanto, correcto el proceder de la generalidad de los diccionarios al incluir bajo el mismo lema tanto una forma como otra, que además tampoco coinciden absolutamente en sus funcionas sintácticas por cuanto que el neutro puede actuar, por ejemplo, como sustituto de un predicado nominal ${ }^{13}$.

13 Véase a este respecto Porto Dapena (1999). 
Naturalmente, no es mi intención entrar aquí en la delicada y compleja cuestión de la distinción entre homonimia y polisemia ${ }^{14}$; pero lo que no parece en modo alguno aconsejable es, como hacen la generalidad de los diccionarios examinados, reunir bajo un mismo lema las formas coincidentes del pronombre de tercera persona y las del artículo. Se nota por cierto también en esto el influjo de la doctrina gramatical de Bello al respecto, quien, como se recordará, interpreta las formas del pronombre personal de tercera persona como puras variantes del artículo, doctrina que, pese a haber sido defendida en tiempos modernos por F. Lázaro Carreter (1980), se encuentra totalmente superada: en realidad las formas $l o(s)$ y $l a(s)$ son funcionalmente muy diferentes cuando acompañan a un nombre que cuando se juntan al verbo. $\mathrm{Y}$, desde luego, menos sentido tiene, como hacen algunos de estos diccionarios, incluir, por ejemplo, bajo el mismo lema la el sustantivo indicador de una nota musical, que nada tiene que ver ni etimológica ni morfológica o funcionalmente con el pronombre personal y menos, por supuesto, con el artículo.

\subsection{LEMATIZACIÓN DEL PRONOMBRE REFLEXIVO}

He dejado aposta sin tratar la forma átona se del pronombre oblicuo de tercera persona (variante de le) porque, debido a su coincidencia fonética y ortográfica con el pronombre reflexivo de la misma persona, plantea el mismo problema de lematización a que me acabo de referir: mientras unos diccionarios registran dos lemas, otros sin embargo los reducen a uno solo. Observemos a este respecto el cuadro de la página siguiente.

De acuerdo con esto, cuatro son exactamente los diccionarios que tratan bajo el mismo lema los dos pronombres, a saber: el Clave, SGEL, Anaya y Alcalá. La mayoría, en cambio, los consideran bajo lemas independientes, los cuales aparecen diferenciados mediante un índice (o número romano): $s e^{l}$ para el reflexivo, y $s e^{2}$ para la variante de $l e(s)$. Cabría plantearse, sin embargo, la existencia de un tercer lema $s e^{3}$, no

14 Existe, como es bien sabido, una amplia bibliografía sobre el tema, de la que se hace una extensa y aguda discusión en la reciente obra de Muñoz Núñez (1999). 


\begin{tabular}{|l|c|c|c|c|}
\cline { 2 - 5 } \multicolumn{1}{c|}{} & se (le) & se & sí & consigo \\
\hline DRAE & + & + & + & + \\
\hline DUE & + & + & + & + \\
\hline DEA & + & + & + & + \\
\hline Clave & - & + & + & + \\
\hline Salamanca & + & + & + & + \\
\hline SGEL & - & + & + & + \\
\hline Anaya & - & + & + & + \\
\hline DUEAE & + & + & + & + \\
\hline Lema & + & + & + & + \\
\hline Alcalá & - & + & + & + \\
\hline DGILE & + & + & + & + \\
\hline DCR & - & - & - & + \\
\hline
\end{tabular}

registrado por ningún diccionario, y que correspondería al llamado se impersonal o pasivo, habida cuenta de que con ese valor semejante partícula ha perdido totalmente su carácter pronominal, dado que, por una parte, no desempeña ninguna función nominal (no es complemento directo ni indirecto ni, por supuesto, sujeto) y, además, no puede conmutar con ninguna forma pronominal ${ }^{15}$. Así pues, aunque esta distinción homonímica no se justifica desde el punto de vista etimológico, puesto que este $s e^{3}$ proviene indudablemente del reflexivo, adquiere sin embargo sincrónicamente una justificación plena desde el punto de vista funcional. En conclusión, una lematización adecuada, a mi juicio, consistiría en distinguir tres signos se, correspondientes por este orden al pronombre reflexivo, a la variante de $l e(s)$ y a la partícula impersonalizadora o de pasiva refleja.

15 Véase a este respecto Porto Dapena (1986: 17 y 19). Puede verse también Gómez Torrego (1992: 28), Otero (1968) y Bobes Naves (1974). 
Fuera del caso de $s e$, los diccionarios, según se desprende del cuadro anterior, no presentan discrepancia alguna en cuanto a la lematización de las formas del pronombre reflexivo: en correspondencia con las formas paralelas de la primera y segunda persona de singular, aparecen lematizadas sípor una parte y consigo por otra, aun cuando ésta no es en realidad más que una variante de aquélla al ser resultado de su aglomeración con la preposición con y go $(<\mathrm{cum})$. Lo único destacable, si acaso, es el hecho de que algunos diccionarios -así, el SGEL y el Anaya, por ejemplo-incluyen bajo el lema síno solo el pronombre, sino también el adverbio de afirmación, cosa desde luego injustificable tanto etimológica como funcionalmente.

\section{EL ARTÍCULO}

Aunque tradicionalmente el artículo es considerado, como es sabido, una parte independiente de la oración, no cabe duda de que, de acuerdo con nuestro concepto de 'pronombre' -esto es, como palabra gramatical con función sustantiva o adjetiva-, nos hallamos en realidad ante un tipo de pronombre, hecho que además se corrobora desde el punto de vista etimológico. Los diccionarios lo clasifican exclusivamente como artículo o determinante artículo, aunque la mayor parte de ellos incluye, como ya hemos visto, bajo el mismo lema las formas coincidentes de éste y del pronombre personal átono de tercera persona.

Por lo que se refiere a la lematización, la situación es la que aparece en el cuadro de la página siguiente.

Como echa de verse, se destacan dos procedimientos básicos: el seguido por la Academia junto con el DUE, el Salamanca, el SGEL y el $D G I L E$, en el que aparecen lematizadas todas y cada una de las formas, y, en segundo lugar, el utilizado por el DEA, Anaya, DUEAE, Lema y Alcalá, en los que aparecen lematizadas todas las formas menos las de plural. Casos independientes son los representados por el Clave, que lematiza todas las formas excepto el femenino singular, y el $D C R$, que no lematiza más que la forma $e l$, al lado de la cual se registran, como sublemas, todas las demás formas, siendo por otro lado el único diccionario donde no aparecen las contracciones aly del. 


\begin{tabular}{|l|c|c|c|c|c|c|c|}
\cline { 2 - 8 } \multicolumn{1}{c|}{} & el & la & lo & los & las & al & del \\
\hline DRAE & + & + & + & + & + & + & + \\
\hline DUE & + & + & + & + & + & + & + \\
\hline DEA & + & + & + & - & - & + & + \\
\hline Clave & + & $o$ & + & + & + & + & + \\
\hline Salamanca & + & + & + & + & + & + & + \\
\hline SGEL & + & + & + & + & + & + & + \\
\hline Anaya & + & + & + & - & - & + & + \\
\hline DUEAE & + & + & + & - & - & + & + \\
\hline Lema & + & + & + & - & - & + & + \\
\hline Alcalá & + & + & + & - & - & + & + \\
\hline DGILE & + & + & + & + & + & + & + \\
\hline DCR & + & $o$ & $o$ & $o$ & $o$ & - & - \\
\hline
\end{tabular}

Ahora bien, esto que parece poner de manifiesto una cierta homogeneidad al menos en cada uno de los dos grupos principales de diccionarios, no es en realidad así, puesto que se encuentran a su vez discrepacias en el encabezamiento correspondiente al lema el. Y así, mientras el $D R A E$ adopta el enunciado complejo

\section{el, la, lo}

esto es, con dos sublemas, los demás diccionarios de su grupo reducen dicho enunciado a tan solo el lema. La misma discrepancia encontramos en el segundo grupo, ya que, mientras los diccionarios Lema, $D U E A E$, Anaya y $D E A$ utilizan el enunciado complejo

\section{el, la}

esto es, con la forma masculina y femenina, el Alcalá registra tan solo el. También el Clave, por su parte, junta la forma femenina con la masculina en el mismo enunciado, y, finalmente, el DCR incluye nada menos que todas las formas del artículo - excepto las contractas-en una única cabecera: 


\section{el, la, lo, los, las.}

Digno de destacar es por cierto el hecho de que ningún diccionario, siguiendo en esto una larga tradición de nuestra gramática normativa, distingue, contra lo que nos obliga la etimología y el aspecto funcional, dos formas homónimas el del artículo: naturalmente la masculina, procedente del lat. ILLE, que es por cierto la única que registran, junto a la femenina, resultado, como es bien sabido, lo mismo que la, del femenino latino ILLA, ya sea a partir de la forma romance antigua ela o por sinalefa en contextos con la preposición $a$ o sobre todo de (de + l'agua). Excepto el $D C R$ de Cuervo, que dedica toda una nota al estudio de esta particularidad, los diccionarios se limitan todo lo más a señalar, como hace por ejemplo el $D E A$, que la forma $e l$ no solo se usa ante nombres masculinos, sino también ante los femeninos que comienzan por $a$ tónica, es decir, como si de una sola forma se tratara. No hace falta insistir en que la identificación de estas formas homónimas, cosa tradicionalmente admitida por nuestras gramáticas y, como se ve, asimismo por la generalidad de los diccionarios incluso actuales, ha llevado al uso anómalo de la forma de masculino de otros determinantes, como un y este, ese, aquel delante de sustantivos femeninos con $a$-inicial tónica ${ }^{16}$. Desde luego, no es necesario señalar que en los diccionarios deberían aparecer como lemas independientes -puesto que de una homonimia se trata- un $e l^{l}$, correspondiente al masculino singular, junto a un $e l^{2}$, alomorfo o variante junto a la del femenino.

\section{LOS DEMOSTRATIVOS}

Pasando ahora a ocuparnos de los pronombres demostrativos, la situación es asimismo relativamente variopinta, como puede observarse a través de los siguientes cuadros:

16 Para el estudio pormenorizado de la cuestión, me remito a Álvarez de Miranda (1993). 
I) Pronombre de cercanía a la primera persona:

\begin{tabular}{|l|c|c|c|c|c|c|c|c|c|c|}
\cline { 2 - 12 } \multicolumn{1}{c|}{} & este & esta & esto & estos & estas & aqueste & aquesta & aquesto & estotro & estotra \\
\hline DRAE & + & $o$ & $o$ & + & - & + & $o$ & - & + & $o$ \\
\hline DUE & + & $o$ & + & - & - & + & $o$ & $o$ & + & $o$ \\
\hline DEA & + & $o$ & + & - & - & - & - & - & + & $o$ \\
\hline Clave & + & $o$ & + & + & - & + & $o$ & + & - & - \\
\hline Salamanca & + & $o$ & $o$ & - & - & - & - & - & - & - \\
\hline SGEL & + & $o$ & + & - & - & - & - & - & + & $o$ \\
\hline Anaya & + & $o$ & + & - & - & - & - & - & - & - \\
\hline DUEAE & + & $o$ & + & - & - & - & - & - & - & - \\
\hline Lema & + & $o$ & + & - & - & - & - & - & - & - \\
\hline Alcalá & + & $o$ & + & - & - & - & - & - & - & - \\
\hline DGILE & + & $o$ & $o$ & $o$ & $o$ & + & $o$ & $o$ & + & $o$ \\
\hline DCR & + & $o$ & $o$ & - & - & + & $o$ & $o$ & + & $o$ \\
\hline
\end{tabular}

II) Pronombre de cercanía a la segunda persona:

\begin{tabular}{|l|c|c|c|c|c|c|c|c|c|c|}
\cline { 2 - 12 } \multicolumn{1}{c|}{} & ese & esa & eso & esos & esas & aquese & aquesa & aqueso & esotro & esotra \\
\hline DRAE & + & $o$ & $o$ & + & - & + & $o$ & - & + & $o$ \\
\hline DUE & + & + & + & - & - & + & $o$ & $o$ & + & $o$ \\
\hline DEA & + & $o$ & + & - & - & - & - & - & + & $o$ \\
\hline Clave & + & $o$ & + & + & - & - & - & - & + & $o$ \\
\hline Salamanca & + & $o$ & $o$ & - & - & - & - & - & - & - \\
\hline SGEL & + & $o$ & + & - & - & - & - & - & + & $o$ \\
\hline Anaya & + & $o$ & + & - & - & - & - & - & - & - \\
\hline DUEAE & + & $o$ & + & - & - & - & - & - & - & - \\
\hline Lema & + & $o$ & + & - & - & - & - & - & - & - \\
\hline Alcalá & + & $o$ & + & - & - & - & - & - & - & - \\
\hline DGILE & + & $o$ & $o$ & $o$ & $o$ & + & $o$ & $o$ & + & $o$ \\
\hline DCR & + & $o$ & $o$ & - & & + & $o$ & $o$ & + & $o$ \\
\hline
\end{tabular}


III) Pronombre de lejanía:

\begin{tabular}{|l|c|c|c|c|c|c|c|c|}
\cline { 2 - 10 } \multicolumn{1}{c|}{} & aquel & aquella & aquello & aquellos & aquellas & aquele & aquela & aquello \\
\hline DRAE & + & $o$ & $o$ & + & - & + & $o$ & - \\
\hline DEA & + & + & + & - & - & + & $o$ & $o$ \\
\hline Clave & + & $o$ & + & - & - & - & - & - \\
\hline Salamanca & + & + & + & + & - & - & - & - \\
\hline SGEL & + & $o$ & $o$ & - & - & - & - & - \\
\hline Anaya & + & $o$ & + & - & - & - & - & - \\
\hline DUEAE & + & $o$ & + & - & - & - & - & - \\
\hline Lema & + & $o$ & + & - & - & - & - & - \\
\hline Alcalá & + & $o$ & + & - & - & - & - & - \\
\hline DGILE & + & $o$ & $o$ & $o$ & $o$ & - & - & - \\
\hline DCR & + & $o$ & $o$ & - & & - & - & - \\
\hline
\end{tabular}

Debe notarse ante todo que en el DGILE aparecen bajo lemas distintos los demostrativos con función adjetiva y sustantiva, de modo que se presenta el siguiente par de enunciados y en este orden:

este, esta, estos, estas

éste, ésta, esto, éstos, éstas

junto, por supuesto, a

ese, esa, esos, esas

ése, ésa, eso, ésos, ésas

aquel, aquella, aquellos, aquellas

aquél, aquélla, aquello, aquéllos, aquéllas

circunstancia que no indico en los cuadros por no multiplicar excesivamente las casillas. 
Comparando ahora los cuadros entre sí, observamos que existen algunas faltas de paralelismo en el tratamiento de estos pronombres por parte de algunos diccionarios:

a)Y así, en el $D U E$ se observa que, mientras los femeninos esa y aquella constituyen lemas independientes, no se registra sin embargo esta.

b) En el $D R A E$ no aparecen registradas como lemas ni como sublemas las formas neutras aquesto, aqueso de los correspondientes demostrativos arcaicos, con lo que se produce una falta de paralelismo con esto, eso, que se registran como sublemas. Tampoco en este diccionario se registra la forma neutra aquelo correspondiente al demostrativo arcaico que aparece bajo el lema aquele.

c) En el $S G E L$ curiosamente se registran con lema independiente los neutros esto y eso, y, si embargo, aquello aparece únicamente como sublema junto a aquel.

d) Por su lado el Clave presenta un par de incoherencias: por una parte presenta como lema independiente la forma femenina aquella, cosa que paralelamente no se produce en los pronombres de cercanía, cuyas respectivas formas femeninas se presentan como sublemas junto a este y ese. Por otra parte resulta asimismo incongruente el registro de los pronombres arcaicos esotro y aqueste, frente a la ausencia de estotro y aquese.

e) Otras incoherencias se refieren a la manera de presentar los sublemas. Así, en el $D C R$, mientras el pronombre correspondiente al de lejanía presenta los sublemas - esto es, las formas femenina y neutra- escritos en su integridad, en los otros dos pronombres, los de cercanía a la primera y segunda personas, se presentan con la mera terminación o desinencia ${ }^{17}$; así, compárense

17 Esta falta de paralelismo podría achacarse a la intervención de personas distintas en la redacción de los respectivos artículos: aquel fue, como es sabido, elaborado por Cuervo, y, en cambio, ese y este lo ha sido por mí mismo. Sin pretender hurtar para nada el grado de responsabilidad que me toca en este nueva incoherencia del $D C R$, debo advertir que, al adoptar esa solución, me atuve al encabezamiento establecido por el pro- 


\section{aquel, aquella, aquello}

frente a

\section{ese, $a, 0$ \\ este, a, 0.}

Otras veces, como ocurre en el DUE, los sublemas se indican en unos pronombres, concretamente en los de cercanía, por medio de las correspondientes desinencias, en tanto que en el de lejanía se utiliza la representación por medio de la última sílaba. Finalmente, en el Lema y $D U E A E$-y lo mismo en el Anaya - se presenta, curiosamente, el sublema mediante la última sílaba en el pronombre de cercanía a la primera persona, es decir,

\section{este, -ta}

mientras en los otros dos pronombres el correspondiente sublema aparece en su forma íntegra:

\section{ese, esa \\ aquel, aquella.}

Pasando ahora a analizar las discrepancias entre los distintos diccionarios, cabe señalar en primer lugar que, mientras unos (así, el $D U E$, $D E A$, Clave, SGEL, Anaya, DUEAE, Lema y Alcalá) registran en lema independiente las formas neutras, no lo hacen en cambio otros, como es el caso del DRAE, Salamanca, DGILE y DCR, que las incluyen únicamente como sublemas junto al masculino. Entre los diccionarios del primer grupo hay, por otro lado, que distinguir a su vez los que interpretan dichas formas como entradas independientes, que son la mayoría, frente al DUE de M. Moliner, quien adopta una postura intermedia al incluir al mismo tiempo los neutros junto a las formas masculina y femenina en un mismo enunciado. Y así, mientras en el primer caso -por ejemplo, en el $D E A$ - tenemos los enunciados

$$
\begin{aligned}
& \text { este, -ta } \\
& \text { esto }
\end{aligned}
$$

pio Cuervo en el material lexicográfico correspondiente a estos pronombres, encabezamiento que responde por cierto al mismo citerio utilizado por el propio maestro colombiano en los casos de aqueste y aquese. 
en el $D U E$, en cambio, aparecen estos otros:

\section{este, - a, $-\mathbf{0}$ \\ esto.}

Como es obvio, la consideración del neutro como entrada independiente obedece al hecho de que esta forma es siempre sustantivo (pronombre, según una concepción muy extendida), mientras que los correspondientes masculinos y femeninos son básicamente adjetivos, aunque también pueden actuar como sustantivos. De ahí la dualidad -con la correspondiente duplicidad de paradigmas- pronombre / adjetivo demostrativo tan extendida en nuestra tradición gramatical, que hoy prácticamente ningún gramático acepta, puesto que tan pronominales son estos deícticos cuando equivalen a sustantivos como cuando equivalen a adjetivos. Observemos de paso que el mismo argumento que lleva a separar las formas neutras como pertenecientes a un paradigma distinto obligaría a distinguir dos formas homónimas -como pronombre y como adjetivo- en las correspondientes masculina y femenina, por lo que en principio resultaría mucho más coherente la solución adoptada por el DGILE cuando separa, como hemos visto, en enunciados distintos y, por lo tanto, como entradas independientes, las funciones sustantiva y adjetiva. Esta solución, con todo, no parece la más adecuada, en primer lugar porque complica innecesariamente la descripción, al tener que repetir en la práctica la misma información bajo una y otra entrada, y, en el caso concreto del DGILE, al presentar las llamadas formas exclusivamente pronominales con acento gráfico, el cual, como es sabido, hoy es meramente potestativo y solo obligatorio en casos de ambigüedad, por lo que no constituye propiamente la marca en el nivel escrito de la función sustantiva frente a la adjetiva: en todo caso habría que registrar, para la función sustantiva, las formas con tilde como variantes junto a las que no la llevan, lo que, evidentemente, complicaría todavía más la cuestión. En conclusión abogamos por la consideración de un único paradigma -y por lo tanto de una sola entrada-para las dos funciones, sustantiva y adjetiva, con la inclusión, por supuesto, de la forma neutra en el mismo enunciado que la masculina y femenina, lo que no obstará para que, al mismo tiempo, sea objeto de lematización independiente (con remisión al correspondiente artículo), como hace M. Moliner. 
Y finalizamos con dos consideraciones sobre la representación gráfica de los sublemas en el enunciado lexicográfico:

a) Como ya hemos señalado anteriormente, éstos se presentan con las formas plenas, como es el caso, por ejemplo, del DGILE, o tan solo mediante la terminación, que a su vez puede aparecer con o sin guión, correspondiente por otro lado o a la desinencia, como por ejemplo en el DUE

$$
\text { este, }-\mathbf{a},-\mathbf{0} \text {, }
$$

o a la última sílaba, como en el $D R A E$

\section{este, ta, to.}

También por cierto en este punto algunos diccionarios presentan incoherencias, al utilizar, según los casos, los dos procedimientos, y así en el propio DUE nos encontramos con el enunciado

\section{aquel, -lla, -llo}

debido, lógicamente, a la necesidad de registrar al mismo tiempo la modificación de la raíz o tema. A propósito de esto último por cierto hay que señalar la curiosa solución adoptada por el Alcaláa propósito de este último pronombre:

\section{aquel, quella}

la cual se justificaría por la necesidad de establecer con precisión la conexión de la terminación con el resto de la palabra, cosa que evidentemente no se consigue con la solución, comúnmente adoptada, del DUE, según la cual podría interpretarse que - lla, -llo sustituirían a la última sílaba de aquel, cuando obviamente no es así. Pienso, no obstante, que para tener que repetir prácticamente todo el tema, excepto la vocal inicial, hubiera sido preferible incluir la forma completa como hacen otros diccionarios. Pero se me ocurre una solución quizá más adecuada y que podría adoptarse como norma general en todos los casos: en lugar de establecer la terminación con la última sílaba, hacerlo a partir de la última letra coincidente del lema, con lo que para el caso que nos ocupa tendríamos esta otra posibilidad, no adoptada hasta ahora por ningún diccionario: 


\section{aquel, -ella, -ello.}

b) La otra consideración se refiere a qué formas de la flexión han de registrarse como sublemas en el enunciado lexicográfico, aspecto en el que existen asimismo discrepacias entre los distintos diccionarios. Fuera del caso ya estudiado de la inclusión o no de la forma neutra, notemos a este respecto que, mientras la generalidad de los diccionarios registran únicamente la forma femenina singular, el DGILE presenta asimismo las formas de plural, tanto en la entrada correspondiente a la función adjetiva como a la sustantiva:

\section{este, esta, estos, estas \\ éste, ésta, esto, éstos, éstas.}

La solución podría justificarse en el caso del masculino plural, por no poderse formar regularmente a partir de la correspondiente forma singular; pero no en el femenino, que es plenamente regular.

\section{LOS POSESIVOS}

Con la variedad de soluciones en la lematización de los demostrativos contrasta la relativa uniformidad con que son tratados en los diccionarios los pronombres posesivos, pese a que estos presentan, desde el punto de vista teórico, una problemática muy semejante a la de aquellos, al corresponderles asimismo la doble función: como sustantivos (o pronombres según muchos) y adjetivos. En este caso, sin embargo, no hay ningún diccionario que establezca lematización independiente para cada una de esas funciones; el hecho, por otro lado, de que, frente a los demostrativos, no presenten una forma específica de neutro facilita - pienso- también la relativa uniformidad con que son tratados. Veamos en los siguientes cuadros las soluciones adoptadas por cada diccionario en particular: 
I) Posesión de la primera persona:

\begin{tabular}{|l|c|c|c|c|c|c|c|c|c|c|}
\cline { 2 - 12 } \multicolumn{1}{c|}{} & mío & mía & míos & mías & mi & mis & nuestro & nuestra & nuestros & nuestras \\
\hline DRAE & + & $o$ & - & - & + & - & + & $o$ & - & - \\
\hline DUE & + & $o$ & - & - & + & - & + & $o$ & - & - \\
\hline DEA & + & $o$ & - & - & + & - & + & $o$ & - & - \\
\hline Clave & + & $o$ & - & - & + & - & + & $o$ & - & - \\
\hline Salamanca & + & $o$ & - & - & + & - & + & $o$ & - & - \\
\hline SGEL & + & $o$ & - & - & + & - & + & $o$ & - & - \\
\hline Anaya & + & $o$ & - & - & + & - & + & $o$ & - & - \\
\hline DUEAE & + & $o$ & - & - & + & - & + & $o$ & - & - \\
\hline Lema & + & $o$ & - & - & + & - & + & $o$ & - & - \\
\hline Alcalá & + & $o$ & - & - & + & - & + & $o$ & - & - \\
\hline DGILE & + & $o$ & - & - & + & $o$ & + & $o$ & $o$ & $o$ \\
\hline DCR & + & $o$ & - & - & - & - & + & $o$ & - & - \\
\hline
\end{tabular}

II) Posesión de la segunda persona:

\begin{tabular}{|l|c|c|c|c|c|c|c|c|c|c|}
\cline { 2 - 12 } \multicolumn{1}{c|}{} & tuyo & tuya & tuyos & tuyas & tu & tus & vuestro & viestra & vuestros & vuestras \\
\hline DRAE & + & $o$ & - & - & + & - & + & $o$ & - & - \\
\hline DUE & + & $o$ & - & - & + & - & + & $o$ & - & - \\
\hline DEA & + & $o$ & - & - & + & - & + & $o$ & - & - \\
\hline Clave & + & $o$ & - & - & + & - & + & $o$ & - & - \\
\hline Salamanca & + & $o$ & - & - & + & - & + & $o$ & - & - \\
\hline SGEL & + & $o$ & - & - & + & - & + & $o$ & - & - \\
\hline Anaya & + & $o$ & - & - & + & - & + & $o$ & - & - \\
\hline DUEAE & + & $o$ & - & - & + & - & + & $o$ & - & - \\
\hline Lema & + & $o$ & - & - & + & - & + & $o$ & - & - \\
\hline Alcalá & + & $o$ & - & - & + & - & + & $o$ & - & - \\
\hline DGILE & + & $o$ & $o$ & $o$ & + & $o$ & + & $o$ & $o$ & $o$ \\
\hline DCR & + & $o$ & - & - & - & - & + & $o$ & - & - \\
\hline
\end{tabular}


III) Posesión de la tercera persona:

\begin{tabular}{|l|c|c|c|c|c|c|}
\cline { 2 - 7 } \multicolumn{1}{c|}{} & suyo & suya & suyos & suyas & su & sus \\
\hline DRAE & + & $o$ & - & - & + & - \\
\hline DUE & + & $o$ & - & - & + & - \\
\hline DEA & + & $o$ & - & - & + & - \\
\hline Clave & + & $o$ & - & - & + & - \\
\hline Salamanca & + & $o$ & - & - & + & - \\
\hline SGEL & + & $o$ & - & - & + & - \\
\hline Anaya & + & $o$ & - & - & + & - \\
\hline DUEAE & + & $o$ & - & - & + & - \\
\hline Lema & + & $o$ & - & - & + & - \\
\hline Alcalá & + & $o$ & - & - & + & - \\
\hline DGILE & + & $o$ & $o$ & $o$ & + & $o$ \\
\hline DCR & + & $o$ & - & - & - & - \\
\hline
\end{tabular}

Como echa de verse, se produce una esencial coincidencia en todos los diccionarios a excepción del DGILE y el DCR. Éste último no lematiza, frente a todos los demás, las formas apocopadas $m i, t u$, su, que trata, junto con las formas plenas, bajo los lemas mío, tuyo, suyo, a los que añade como sublemas los correspondientes femeninos en sus formas íntegras, es decir,

\section{mío, mía \\ tuyo, tuya \\ suyo, suya.}

Esta solución por cierto choca con la dada en el caso de los posesivos referidos a varios poseedores de primera y segunda persona, los cuales también se hallan lematizados con las formas masculinas acompañadas, como sublemas, de las correspondientes femeninas, pero representadas únicamente por la desinencia: 


\section{nuestro, a \\ vuestro, a.}

Por su lado las particularidades del DGILE se centran ante todo en el registro como sublemas no solo de las formas femeninas, sino también de los correspondientes plurales, a excepción -sin duda por descuido- de mío, al lado del cual se consigna únicamente la forma mía. Es decir, tenemos:

\section{mío, mía;}

pero, en cambio,

\section{tuyo, tuya, tuyos, tuyas}

suyo, suya, suyos, suyas.

Como puede verse, se adopta además la indicación de los sublemas en sus formas íntegras, solución que se contradice por cierto con la adoptada para los pronombres indicadores de varios poseedores:

\section{nuestro, -tra, -tros, -tras \\ vuestro, -tra, -tros, -tras}

en los que se utiliza únicamente las terminaciones (última sílaba). No hace falta, finalmente, señalar que las formas apocopadas no solo se lematizan aparte, sino que en los respectivos enunciados se incluye también, como sublema, la forma plural:

\section{mi, mis \\ tu, tus \\ su, sus.}

Las discrepancias, que las hay, entre el resto de los diccionarios se refieren por cierto únicamente a la manera de indicar los sublemas. Así, mientras en unos casos se adopta la forma íntegra, en otros se prefiere la terminación, representada unas veces por la última sílaba (en el caso de mía también las dos últimas) o por la simple desinencia. En un mismo diccionario pueden incluso encontrarse las dos soluciones, surgiendo así algunas incoherencias. Tal es el caso, por ejemplo, del Anaya así como del DUEAE y Lema, que utilizan la forma plena en

\section{mío, mía}


y, sin embargo, prefieren la terminación en los demás casos:

$$
\begin{aligned}
& \text { tuyo, -ya } \\
& \text { suyo, -ya }
\end{aligned}
$$

etc. Es de suponer que la indicación del femenino que aparecen en el $S G E L$ en

\section{vuestro, -ra}

constituye una errata consistente en la elisión de $t$, que sin embargo aparece en

\section{nuestro, -tra.}

Curiosa resulta por cierto la solución dada en este diccionario para el caso de

$$
\text { mío, -ía, }
$$

incluyendo, como ya he señalado, en la terminación del femenino las dos últimas sílabas, solución que se justificaría por la necesidad de indicar la conexión de la terminación con el resto de la palabra; pero, al estar éste representado únicamente por $m$-, parecería más justificable indicar el femenino con la forma completa.

De los diccionarios que prefieren el uso de la mera terminación para la indicación de los sublemas, solo uno, el $D E A$, prefiere hacerlo con la desinencia correspondiente, la cual siempre aparece precedida de un guión y sin coma. En los demás casos se prefiere en general la indicación por medio de la última sílaba, que en unos casos aparece también precedida de guión y en otros no. Este último procedimiento es el adoptado, por ejemplo, por el DRAE así como por el Clave, Salamanca y Alcalá.

\section{RELATIVOS E INTERROGATIVOS}

Los problemas de lematización se extienden asimismo al caso de los pronombres relativos e interrogativos debido más que nada a las vacilaciones de los gramáticos a la hora de separar ambas clases de pronombres, considerados en realidad por muchos como un único paradigma aunque con esa doble -e incluso a veces triple- función: como relativos, 
interrogativos y, en algunos casos, también como indefinidos ${ }^{18}$. Pues bien, tales vacilaciones se manifiestan, como no podría ser de otro modo, en los diccionarios e incluso en ocasiones dentro de una misma obra, produciéndose así las consiguientes incoherencias. La situación es la que aparece en los siguientes esquemas, donde al lado de los pronombre incluimos los adverbios relativos e interrogativos:

\begin{tabular}{|l|c|c|c|c|c|c|c|c|c|}
\cline { 2 - 11 } \multicolumn{1}{l|}{} & que & qué & cual & $\begin{array}{c}\text { (el, la,lo) } \\
\text { cual }\end{array}$ & cuales & cuál & cuáles & quien & quién \\
\hline DRAE & + & - & - & + & - & - & - & + & - \\
\hline DUE & + & - & - & + & - & - & - & + & - \\
\hline DEA & + & + & + & + & - & + & - & + & + \\
\hline Clave & + & + & - & + & - & + & - & + & + \\
\hline Salamanca & + & + & - & + & - & + & - & + & + \\
\hline SGEL & + & + & - & + & - & + & - & + & + \\
\hline Anaya & + & + & - & + & - & + & - & + & + \\
\hline DUEAE & + & + & - & + & - & + & - & + & + \\
\hline Lema & + & + & - & + & - & + & - & + & + \\
\hline Alcalá & + & + & - & + & - & + & - & + & + \\
\hline DGILE & + & + & - & + & $o$ & + & $o$ & + & + \\
\hline DCR & + & - & - & + & - & - & - & + & - \\
\hline
\end{tabular}

18 Así los interpretan, por ejemplo, Bello (1981: 275) y Alcina y Blecua (1975: 788 y ss.). Alarcos (1994: 98 y ss.), aunque reconoce su común origen, observa que se trata de paradigmas autónomos: desempeñan funciones distintas, pero a su vez, pese a su parecido fónico, en realidad presentan significantes diferentes, ya que unos son átonos y otros tónicos. Conviene no olvidar, sin embargo, que no todos los relativos son átonos (cual de el cual es tónico, como observa Navarro Tomás 1968: 191) y, al mismo tiempo, también puede postularse un que interrogativo átono, como creo haber demostrado en otro lugar (véase Porto Dapena 2000). 


\begin{tabular}{|l|c|c|c|c|c|c|c|c|}
\cline { 2 - 10 } \multicolumn{1}{c|}{} & cuyo & cuya & cuyos & cuyas & cúyo & cúya & cúyos & cúyas \\
\hline DRAE & + & $o$ & - & - & - & - & - & - \\
\hline DUE & + & $o$ & - & - & - & - & - & - \\
\hline DEA & + & $o$ & - & - & + & $o$ & - & - \\
\hline Clave & + & $o$ & - & - & - & - & - & - \\
\hline Salamanca & + & $o$ & - & - & - & - & - & - \\
\hline SGEL & + & $o$ & - & - & + & $o$ & - & - \\
\hline Anaya & + & $o$ & - & - & - & - & - & - \\
\hline DUEAE & + & $o$ & - & - & + & $o$ & - & - \\
\hline Lema & + & $o$ & - & - & + & $o$ & - & - \\
\hline Alcalá & + & $o$ & - & - & - & - & - & - \\
\hline DGILE & + & $o$ & $o$ & $o$ & + & $o$ & $o$ & $o$ \\
\hline DCR & + & $o$ & - & - & - & - & - & - \\
\hline
\end{tabular}

\begin{tabular}{|l|c|c|c|c|c|c|c|c|}
\cline { 2 - 10 } \multicolumn{1}{l|}{} & cuan & cuán & $\begin{array}{c}\text { cuanto } \\
\text { (sust.) }\end{array}$ & $\begin{array}{c}\text { cuánto } \\
(\mathrm{adv} .)\end{array}$ & cuanto & cuanta & cuánto & cuánta \\
\hline DRAE & + & - & - & - & + & $o$ & - & - \\
\hline DUE & + & + & - & - & + & $o$ & + & $o$ \\
\hline DEA & + & $o$ & - & - & + & $o$ & + & $o$ \\
\hline Clave & + & + & - & - & + & $o$ & + & $o$ \\
\hline Salamanca & + & + & + & + & + & $o$ & + & $o$ \\
\hline SGEL & + & + & - & - & + & $o$ & + & $o$ \\
\hline Anaya & + & + & - & - & + & $o$ & + & $o$ \\
\hline DUEAE & + & + & - & - & + & $o$ & + & $o$ \\
\hline Lema & + & + & - & - & + & $o$ & + & $o$ \\
\hline Alcalá & + & + & - & - & + & $o$ & + & $o$ \\
\hline DGILE & + & $o$ & - & - & + & $o$ & + & $o$ \\
\hline DCR & $o$ & - & - & - & + & $o$ & - & - \\
\hline
\end{tabular}




\begin{tabular}{|l|c|c|c|c|c|c|c|c|c|c|c|c|c|}
\cline { 2 - 12 } & $\begin{array}{r}\text { cuando } \\
(\text { átono })\end{array}$ & cuando & $\begin{array}{c}\text { cuándo } \\
\text { (tónico })\end{array}$ & como & cómo & donde & dond & onde & $d o$ & 0 & dónde & adonde & adónde \\
\hline DRAE & + & - & - & + & - & + & + & - & - & - & - & + & - \\
\hline DUE & + & - & + & + & + & + & + & - & - & - & + & + & - \\
\hline DEA & + & + & + & + & + & + & - & - & - & - & + & + & + \\
\hline Clave & + & - & + & + & + & + & - & - & - & - & + & + & + \\
\hline Salamanca & + & - & + & + & + & + & - & - & - & - & + & + & + \\
\hline SGEL & + & - & + & + & + & + & - & - & - & - & + & + & + \\
\hline Anaya & + & - & + & + & + & + & - & - & - & - & + & + & + \\
\hline DUEAE & + & - & + & + & + & + & - & - & - & - & + & + & + \\
\hline Lema & + & - & + & + & + & + & - & - & - & - & + & + & + \\
\hline Alcalá & + & - & + & + & + & + & - & - & - & - & + & + & + \\
\hline DGILE & + & - & + & + & - & + & - & - & - & - & - & + & - \\
\hline DCR & + & - & - & + & - & + & - & 0 & 0 & 0 & - & + & - \\
\hline
\end{tabular}

Como puede verse fácilmente, parten de la identificación de relativos e interrogativos el $D R A E$ y el $D C R$, con la diferencia de que este último registra la forma cuan (que a su vez incluye a cuán) como sublema junto a cuánto. También el DUE sigue el mismo criterio, pero comete una incoherencia con cuanto y cuánto -y lo mismo con cuan y cuán-, que considera, sin embargo, lemas independientes. Todos los demás diccionarios consideran independientemente los relativos y los interrogativos, lo que a nuestro juicio constituye la solución más adecuada no solo porque de hecho ambos tipos de pronombres forman parte de paradigmas independientes, sino porque gráficamente -y lo mismo fonéticamente- llevan acento $\mathrm{y}$, por lo tanto, poseen una fisonomía también diferente.

En este último grupo de diccionarios debemos destacar además que algunos (Clave, Anaya y Alcalá), en el caso de cuyo, registran únicamente el relativo, debido sin duda al carácter arcaico del correspon- 
diente interrogativo. También el DGILE registra en un mismo enunciado las formas cuan y cuán (esta última como sublema), lo que presenta una evidente falta de paralelismo con los otros relativos e interrogativos, que lematiza independientemente. Cabe notar asimismo que el diccionario Salamanca, a propósito de cuanto distingue no solo los adjetivos interrogativo y relativo, sino que incluye, también en lemas independientes, los adverbios correspondientes, que, curiosamente, categoriza como sustantivo en el caso del relativo, y como adverbio en el del interrogativo. Finalmente, debemos señalar que el $D E A$ distingue con lemas independientes el relativo cual, de carácter átono y sin artículo, al lado de cual tónico y que va siempre acompañado de artículo, aun cuando este último no figura en el enunciado del artículo, sino en la microestructura, introduciéndolo como en una especie de subentrada; esto es,

\section{cual $[. .$.$] 1. el \sim$, la $\sim$, lo $\sim$.}

Pensamos que esta separación no se justifica y, por lo tanto, este último debería, a nuestro juicio, ser tratado como una subentrada bajo un único cual.

Refiriéndonos por cierto a la forma de los enunciados, evidentemente los relativos e interrogativos invariables -por ejemplo, que y quéaparecen, como no podría ser de otro modo, en su única forma, que constituye por lo tanto el lema. Pero los pronombres variables se presentan asimismo en una única forma, el singular, cuando su variabilidad se refiere únicamente al número; pero con una excepción, la del $D G I L E$, que incluye como sublemas los plurales cuales y cuáles junto a los correspondiente singulares, cual, cuál, que actúan como verdaderos lemas. La inclusión como sublemas de las formas de plural se registran asimismo en este diccionario en los casos en que hay variabilidad de género, de modo que, por ejemplo, tenemos:

\section{cuyo, -ya, cuyos, -yas}

donde, curiosamente, los femeninos se representan en la pura terminación y, en cambio, el plural en su forma íntegra. Esto choca por cierto con la solución adoptada en 


\section{cuanto, -ta \\ cuánto, -ta}

en los que no aparece la forma plural, cosa que, contra lo que era de esperar, ocurre asimismo con

\section{quien}

cuyo enunciado se reduce únicamente al lema. En resumidas cuentas, no existen, como puede verse, tampoco en este caso unos criterios fijos y seguros de lematización.

Sobre el relativo que cabe señalar que la mayor parte de los diccionarios no lo distinguen, en la macroestructura, de la conjunción - o conjunciones- homónima, estudiando ambos elementos bajo el mismo lema. Solo el DEA, DGILE, DUEAE y Lema separan las dos funciones en artículos independientes. Ahora bien, consideraciones etimológicas aparte, desde Alarcos (1970: 192 y ss.) sabemos que, funcionalmente hablando, existen tres signos que diferentes: un que, conjunción completiva o sustantivadora, un que relativo adjetivador, y un que ${ }_{3}$ conjunción comparativa, los cuales lógicamente deberían dar lugar en los diccionarios a otros tantos artículos, lo que significa que deberían ser lematizados independientemente. Por otro lado, en relación con la función relativa, conviene señalar además la existencia junto a que, o relativo simple, de un el que compuesto -distinto de el que de sustantivación, que constituye un uso del primero ${ }^{19}$, si bien a efectos de lematización ello no supondrá ninguna novedad, ya que el relativo compuesto habrá de ser, lógicamente, considerado como subentrada dentro del artículo encabezado por que.

Lo que sí, en cambio, podría implicar la introducción de un nuevo lema que sería la aceptación de la existencia en español de un interrogativo que átono ${ }^{20}$, presente en contextos como

No sé el día que vino

19 Véase, por ejemplo, Porto Dapena (1997: 27).

20 Véase Porto Dapena (2000). 
donde que no es propiamente un relativo, sino una variante del interrogativo qué, con el que se halla en distribución complementaria: éste aparece en posición antenominal y sin artículo (No sé qué día vino) y aquél, que también es un adjetivo, se usa en posición posnominal y exige la presencia del artículo. Este que interrogativo debería, pues, dar lugar a un nuevo lema o, al menos, registrarse como sublema al lado de qué. Evidentemente, ninguno de estos dos procedimientos ha sido adoptado todavía por ningún diccionario.

Y ya para terminar con la consideración de relativos e interrogativos, debemos incluir también aquí -por presentar problemas paralelos- los correspondientes adverbios, como de hecho aparecen en los cuadros expuestos más arriba. A este respecto podemos hacer las siguientes observaciones:

a) En primer lugar sólo el diccionario Salamanca distingue mediante lemas distintos cuanto como sustantivo, adjetivo y adverbio, distinción que, sin embargo, no realiza en el interrogativo correspondiente ni, desde luego, en qué e incluso en el relativo que.

b) Debe resaltarse que el $D E A$, donde, como hemos visto, se registran bajo lemas distintos los relativos e interrogativos, hace sin embargo una excepción con cuan / cuán, que introduce juntos en un mismo enunciado debido, probablemente, a que en ambos casos, que estarían seguidos si se tratasen como lemas distintos, se remite a cuanto y cuánto. Lo coherente, sin embargo, hubiera sido sin duda separarlos en remisiones distintas, pues distintos son los artículos a que se remite.

c) Otra particularidad digna de destacarse también en el $D E A$ es la separación en lemas distintos de cuando átono y cuando tónico (distinto del interrogativo cuándo) -caso paralelo al de cual / el cual-, aun cuando creo que no se justifica: ambas posibilidades responden en realidad a diferentes usos de un mismo signo.

d) Otras particularidades, finalmente, se refieren al registro de ciertos arcaísmos por parte de algunos diccionarios: dond, onde, do, o. Es curioso a este respecto señalar que, mientras estos tres últimos son re- 
cogidos exclusivamente por el $D C R$-eso sí, como sublemas de don$d e-$, este diccionario, siendo histórico, no recoge la forma dond, que aparece en cambio en diccionarios sincrónicos como el $D R A E$ y el DUE.

\section{PRONOMBRES INDEFINIDOS}

En cuanto a los pronombres indefinidos, las discrepancias entre los diccionarios son menos numerosas que en los demás pronombres. Aquí tan solo me voy a ocupar de aquellos que por una u otra razón presentan algún tipo de peculiaridad en este sentido al comparar unos diccionarios con otros. Veámoslo en los siguientes cuadros:

\begin{tabular}{|c|c|c|c|c|c|c|c|c|c|c|c|c|c|}
\hline & nadi & nadie & ninguin & ninguno & ninguna & $\begin{array}{l}\text { sólo } \\
\text { o solo }\end{array}$ & solo & sola & un & uno & una & unos & unas \\
\hline DRAE & + & + & + & + & $o$ & + & + & $o$ & + & + & 0 & - & - \\
\hline$D U E$ & + & + & + & + & 0 & - & + & $o$ & + & + & $o$ & - & - \\
\hline$D E A$ & - & + & + & + & $o$ & - & + & $o$ & + & + & $o$ & - & - \\
\hline Clave & - & + & + & + & 0 & + & + & 0 & + & + & $o$ & - & - \\
\hline Salamanca & - & + & + & + & 0 & - & + & 0 & + & + & $o$ & - & - \\
\hline SGEL & - & + & + & + & 0 & + & + & 0 & + & + & $o$ & - & - \\
\hline Anaya & - & + & + & + & 0 & + & + & 0 & + & + & $o$ & - & - \\
\hline DUEAE & - & + & + & + & $o$ & + & + & 0 & + & + & 0 & - & - \\
\hline Lema & - & + & + & + & $o$ & + & + & 0 & + & + & $o$ & - & - \\
\hline Alcalá & - & + & + & + & 0 & + & + & $o$ & + & + & + & - & - \\
\hline DGILE & - & + & + & + & $o$ & + & + & $o$ & + & + & $o$ & - & - \\
\hline$D C R$ & - & + & - & + & 0 & - & - & - & - & + & 0 & 0 & 0 \\
\hline
\end{tabular}




\begin{tabular}{|l|c|c|c|c|c|c|}
\cline { 2 - 7 } \multicolumn{1}{c|}{} & algo & alguien & algún & algund & alguno & alguna \\
\hline DRAE & + & + & + & - & + & o \\
\hline DUE & + & + & + & + & + & $o$ \\
\hline DEA & + & + & - & - & + & 0 \\
\hline Clave & + & + & + & - & + & 0 \\
\hline Salamanca & + & + & + & - & + & 0 \\
\hline SGEL & + & + & + & - & + & $o$ \\
\hline Anaya & + & + & + & - & + & 0 \\
\hline DUEAE & + & + & + & - & + & 0 \\
\hline Lema & + & + & + & - & + & $o$ \\
\hline Alcalá & + & + & + & - & + & $o$ \\
\hline DGILE & + & + & + & - & + & $o$ \\
\hline DCR & + & + & - & - & + & $o$ \\
\hline
\end{tabular}

\begin{tabular}{|l|c|c|c|c|c|c|c|c|c|}
\cline { 2 - 10 } \multicolumn{1}{l}{} & $\begin{array}{c}\text { cuales- } \\
\text { quier }\end{array}$ & $\begin{array}{c}\text { cuales- } \\
\text { quiera }\end{array}$ & $\begin{array}{c}\text { cualis- } \\
\text { quiera }\end{array}$ & $\begin{array}{c}\text { cual- } \\
\text { que }\end{array}$ & $\begin{array}{c}\text { cual- } \\
\text { quier }\end{array}$ & $\begin{array}{c}\text { cual- } \\
\text { quiera }\end{array}$ & $\begin{array}{c}\text { quien- } \\
\text { quier }\end{array}$ & $\begin{array}{c}\text { quien- } \\
\text { quiera }\end{array}$ & $\begin{array}{c}\text { quienes- } \\
\text { quiera }\end{array}$ \\
\hline DRAE & - & - & - & - & + & + & + & + & - \\
\hline DUE & + & $o$ & - & - & + & + & + & + & + \\
\hline DEA & + & $o$ & + & - & - & + & - & + & - \\
\hline Clave & + & + & - & - & + & + & - & + & + \\
\hline Salamanca & + & + & - & - & + & + & - & + & + \\
\hline SGEL & + & + & - & - & + & + & - & + & - \\
\hline Anaya & - & - & - & - & + & + & - & + & - \\
\hline DUEAE & + & + & - & - & + & + & - & + & + \\
\hline Lema & + & + & - & - & + & + & - & + & + \\
\hline Alcalá & - & - & - & - & + & + & - & + & - \\
\hline DGILE & + & + & - & + & + & + & - & + & - \\
\hline DCR & - & - & - & + & - & + & - & + & - \\
\hline
\end{tabular}


En el primer cuadro se observa bastante regularidad: coinciden la mayor parte de los diccionarios, concretamente el Clave, SGEL, Anaya, DUEAE, Lema y DGILE, que lematizan las formas nadie, ningún, ninguno, sólo, solo, un y uno, tratando a su vez como sublemas las formas femeninas ninguna, sola y una, que aparecen al lado de sus correspondientes masculinos. Con ellos coinciden también el DRAE, DUE, Salamanca y Alcalá, pero con la diferencia de que los dos primeros registran además, con lema independiente, la forma arcaica nadi, mientras que, por una parte, el Salamanca no registra en lema aparte el adverbio sólo, y, por otra, el Alcalá incluye como lema la forma una, aunque solo como femenino de un y distinta, por lo tanto, de la que se registra como sublema al lado de uno. Los demás diccionarios tienen también en cuenta la existencia de estas dos formas una, que no aparecen en el cuadro por falta de espacio, pero con la diferencia de que ambas aparecen como sublemas al lado de un y uno, respectivamente. Al igual de lo que hemos venido observando en la lematización de otros pronombres, el diccionario más discordante es el del Cuervo, al no lematizar más que las formas nadie, ninguno y uno, registrando curiosamente al lado de este último no solo la variante femenina -como hace en el caso de ninguno-, sino también los correspondientes plurales; es decir,

\section{ninguno, na}

frente a

\section{uno, a, os, as}

en que además se varía el criterio de la terminación, con la consiguiente falta de homogeneidad. Finalmente, un aspecto discrepante entre los diccionarios, aparte de la manera de registrar los sublemas -como ocurre, según ya vimos, en otras ocasiones-, es el del orden de registro de las formas sólo o solo (adv.) y solo (adj.) en los diccionarios que las consideran entradas independientes, pues mientras en unos aparece en primer lugar el adverbio, en otros lo hace el adjetivo.

Consideración aparte merece el caso de un / uno, que, mientras unos diccionarios, como por ejemplo el DRAE, los juzgan como signos independientes - por lo que dan lugar a sendos artículos-, para otros -por ejemplo el $D E A$ - se trata de variantes de un mismo signo, de donde que 
efectúen una simple remisión de un a uno, lo mismo que ocurre en las parejas algún / alguno, y ningún / ninguno, considerados en este caso unánimemente como variantes de las mismas palabras. Una y otra solución depende, como es obvio, de la aceptación o no del llamado "artículo indeterminado", que correspondería a un, una, frente al pronombre indefinido uno, una, lo que por otro lado explicaría la existencia de las dos formas femeninas una a que aludíamos antes. Sin entrar ahora en la discusión teórica al respecto, yo me inclinaría por la solución más sencilla, que es sin duda la consideración de un / una como variantes del mismo pronombre, es decir, tal como procede el $D E A$. Poco hay que observar a propósito del segundo cuadro, ya que en este caso se da una práctica unanimidad, a no ser que que, por una parte, el $D U E$ registra la forma arcaica algund con lema independiente, y, por otra, tanto el $D E A$ como el $D C R$ no lematizan la forma algún ni registran algund, que en realidad no aparece más que en el $D U E$.

Más complejo se nos presenta el último cuadro en el que se recogen los pronombres cualquiera y quienquiera. Las discrepancias giran en este caso en torno a la cuestión de considerar en lemas independientes por una parte los plurales y, por otra, las formas apocopadas cualquier y quienquier. Solo un diccionario en realidad, el $D C R$, prescinde de estos dos tipos de variantes, reduciendo la lematización a las formas plenas de singular, sin ni siquiera incluir las otras como sublemas, solución que desde luego no parece la más adecuada. Sin embargo el $D R A E$ junto con el Alcalá prescinden de las formas de plural, reduciéndose a las plenas y apocopadas, solución que resulta suficiente, toda vez que los correspondientes plurales, pese a ser irregulares, son fácilmente identificables con variantes de las formas singulares y en todo caso deberán ponerse de manifiesto en la microestructura de los respectivos artículos. Más adecuada de todas formas es la solución, llevada a cabo por la mayoría de los diccionarios, de incluir también como lemas los plurales, con remisión a los correspondientes singulares, al lado de los cuales no será necesario que reaparezcan como sublemas siempre que, como digo, se registren en la microestructura. 


\section{CONCLUSIÓN}

En resumen y conclusión, como advertía al principio y acabamos de comprobar a lo largo de las páginas que preceden, no existen unos criterios unánimemente aceptados - ni siquiera muchas veces homogéneamente aplicados dentro de una misma obra- a la hora de llevar a cabo la lematización de los pronombres en los diccionarios actuales. Es cierto que bajo esa falta de unanimidad y coherencia laten con frecuencia algunos -a veces viejos- problemas que la teoría gramatical no ha podido o no ha sabido todavía resolver, pero no es menos cierto que en otras ocasiones los desajustes no pueden achacarse más que a la pura desidia o falta de atención por parte de los redactores de diccionarios. No se nos puede ocultar que éstos deben siempre perseguir unos objetivos eminentemente prácticos, al margen muchas veces de las disputas teóricas de los lingüistas -a las que, sin embargo, no pueden ser ajenos-; pero, precisamente por razones prácticas, es indispensable que el lexicógrafo disponga de unas normas o criterios fijos (iguales para todos), a los que a su vez habrá de atenerse el usuario del diccionario, si no se quiere que las consultas de éste se vean convertidas en un mero ejercicio de adivinación o de puro azar. Sin duda la fijación de unas normas de lematización en el caso de los pronombres es, dentro de nuestra lexicografía, un problema pendiente que, como acabamos de comprobar, está pidiendo una solución urgente. 
BIBLIOGRAFÍA

Alarcos Llorach, E. (1970): "Español 'que"”, en Estudios de gramática funcional del español, Madrid, Gredos, pp. 192-206.

(1994): Gramática de la lengua española, Madrid, Espasa-Calpe.

Alcalá: Moreno Fernández, F. (dir.) (1995): Diccionario para la enseñanza de la lengua española, Alcalá de Henares-Barcelona, Universidad de Alcalá de Henares-Biblograf.

Alcina Franch, J. y J. M. Blecua (1975): Gramática española, Barcelona, Ariel.

Alvar Ezquerra, M. (1993): "Diccionario y gramática”, en Lexicografia descriptiva, Barcelona, Biblograf, pp. 87-143.

Álvarez de Miranda, P. (1993): "El alomorfo de la y sus consecuencias", LEA, XV/1, pp. 5-43.

Álvarez MarTíneZ, M. A. (1984): "El pronombre español, ¿categoría funcional?", Español Actual, 42, pp. 49-67.

Anaya (2000): Diccionario de secundaria y bachillerato de la lengua española, Barcelona, Biblograf.

BARRENECHEA, A. M. (1969): "El pronombre y su inclusión en un sistema de categorías semánticas", en sus Estudios de gramática estructural, Buenos Aires, Paidós, pp. 27-70.

Bello, A. (1981): Gramática de la lengua castellana destinada al uso de los americanos, ed. de R. Trujillo, La Laguna, Cabildo Insular de Tenerife.

Benveniste, E. (1973): "La naturaleza de los pronombres", en Problemas de lingüistica general (I), México, Siglo XXI, pp. 172-178.

Bobes NAVES, M. C. (1974): "Construcciones castellanas con se. Análisis transformacional", REL, 4/1, pp. 87-127, y 4/2, pp. 301-325.

Clave: Maldonado, C. (dir.) (1997): Diccionario de uso del español actual, Madrid, SM.

DCR: CuerVo, R. J. (1886-1994): Diccionario de construcción y régimen de la lengua castellana, Bogotá, Instituto Caro y Cuervo.

DEA: Seco, M. et al. (1999): Diccionario del español actual, Madrid, Aguilar.

DGILE: Alvar EzQuerra, M. (1991): Vox. Diccionario general e ilustrado de la lengua española, Barcelona, Biblograf.

DRAE: Real ACADEMia Española (200122): Diccionario de la lengua española, Madrid, Espasa Calpe.

DUE: Moliner, M. (1998): Diccionario de uso del español, Madrid, Gredos. 
DUEAE: BatTaner ARias P. (dir.) (2002): Diccionario de uso del español de América y España, Barcelona, Spes Editorial.

ESCAVY ZAMORA, R. (1987): El pronombre. Categorías y funciones pronominales en la teoría gramatical, Murcia, Universidad de Murcia.

GILI GaYA, S. (1954): "Prólogo" al Diccionario manual ilustrado de la lengua española, Barcelona, Biblograf.

Gómez TORREGO, L. (1992): Valores gramaticales de "se", Madrid, Arco/Libros.

HJeLMSLEv, L. (1972): "La naturaleza del pronombre”, en Ensayos lingüissticos, Madrid, Gredos, pp. 253-261.

LÁZARO CARRETER, F. (1980): "El problema del artículo en español: una lanza por Bello", en Estudios de Lingü̈stica, Barcelona, Crítica, pp. 27-59.

Lema: BATTANeR, P. (dir). (2001): Diccionario de la lengua española "Lema", Barcelona, Spes Editorial.

Llorente, A. y J. MondÉJAR (1974): “La conjugación objetiva en español", REL, 4/1, pp. 1-60.

Molina, J. A. de (1978): "El pronombre como categoría funcional", en $E s$ tudios ofrecidos a E. Alarcos Llorach, III, Oviedo, Universidad de Oviedo, pp. 237-253.

MONDÉJAR, J. (1977): "Sobre la naturaleza gramatical del pronombre en español", REL, 7/1, pp. 37-55.

MuÑoz NúÑEz, M. D. (1999): La polisemia léxica, Cádiz, Universidad de Cádiz.

NAVARro TomÁs, T. $\left(1968^{14}\right)$ : Manual de pronunciación española, Madrid, C.S.I.C.

OlzA, J. (1973): El pronombre, Caracas, Universidad Católica Andrés Bello.

OTERo, C. P. (1968): "El otro se", en Actas del XI Congreso Internacional de Lingüistica y Filología Románicas, IV, Madrid, C.S.I.C., pp. 1841-1849.

Porto Dapena, J. A. (1980): Elementos de Lexicografia: el Diccionario de construcción y régimen de R. J. Cuervo, Bogotá, Instituto Caro y Cuervo.

_ (1986): Los pronombres, Madrid, Edi-6.

(1997): Relativos e interrogativos, Madrid, Arco/Libros.

(1999): "El pronombre neutro lo como sustituto del predicado nominal", en Lengua y discurso. Estudios dedicados al profesor Vidal Lamíquiz, Madrid, Arco/Libros, pp. 761-772. 
_ (2000): “¿Existe un que interrogativo átono en español actual?”, LEA, XXII/1, pp. 5-21.

- (2002): Manual de técnica lexicográfica, Madrid, Arco/Libros.

Real ACAdEMia Española (1962): Gramática de la lengua española, nueva ed. reformada de 1931, Madrid, Espasa-Calpe.

_ (1973): Esbozo de una nueva gramática de la lengua española, Madrid, Espasa-Calpe.

Salamanca: GutiÉRREZ CuAdRADO, J. (dir) (2000): Diccionario "Salamanca" de la lengua española, Madrid, Santillana-Universidad de Salamanca.

SGEL: SÁNCHEZ, A. (dir.) (2001): Gran diccionario de uso del español actual, Madrid, SGEL. 